seen is simply this, that if an analyser is arranged to stop the light and make the field quite dark before the magnet is excited, then directly the battery is connected and the magnet called into action a faint and barely perceptible brightening of the field occurs; which will disappear if the analyser be slightly rotated. [The experiment was then shown.] Now no wonder that no one understood this result. Faraday himself did not understand it at all : he seems to have thought that the magnetic lines of force were rendered luminous, or that the light was magnetised; in fact he was in a fog, and had no idea of its real significance. Nor had any one. Continental philosophers experienced some difficulty and several failures before they were able to repeat the experiment. It was in fact discovered too soon, and before the scientific world was ready to receive it, and it was reserved for Sir William Thomson briefly, but very clearly, to point out, and for Clerk Maxwell more fully to develop, its most important consequences. [The principle of the experiment was then illustrated by the aid of a mechanical model.]

This is the fundamental experiment on which Clerk Maxwell's theory of light is based; but of late years many fresh facts and relations between electricity and light have been discovered, and at the present time they are tumbling in in great numbers.

It was found by $\mathrm{F}$ araday that many other transparent media besides heavy glass would show the phenomenon if placed between the poles, only in a less degree; and the very important observation that air itself exhibits the same phenomenon, though to an exceedingly small extent, has just been made by Kundt and Röntgen in Germany.

Dr. Kerr of Glasgow has extended the result to opaque bodies, and has shown that if light be passed through magnetised iron its plane is rotated. The film of iron must be exceedingly thin, because of its opacity, and bence, though the intrinsic rotating power of iron is undoubtedly very great, the observed rotation is exceedingly small and difficult to observe; and it is only by very remarkable patience and eare and ingenuity that Dr. Kerr has obtained his result. Mr. Fitzgerald of Dublin has examined the question mathematically, and has shown that Maxwell's theory would have enabled Dr. Kerr's result to be predicted.

Another requirement of the theory is that kodies which are transparent to light must be insulators or non-conductors of electricity, and that conductors of electricity are necessarily opaque to light. Simple observation amply confirms this; metals are the best conductors, and are the most opaque bodies known. Insulators such as glass and crystals are transparent whenever they are sufficiently homogeneous, and the very remarkable researches of Prof. Graham Bell in the last few months have shown that even ebonite, one of the most opaque insulators to ordinary vision, is certainly transparent to some kinds of radiation, and transparent to no small degree.

[The reason why transparent bodies must insulate, and why conductors must be opaque, was here illustrated by mechanical models.]

A further consequence of the theory is that the velocity of light in a transparent medium will be affected by its electrical strain constant; in other words, that its refractive index will bear some close but not yet quite ascertained relation to its specific inductive capacity. Experiment has partially confirmed this, but the confirmation is as yet very incomplete. But there are a number of results not predicted by theory, and whose connection with the theory is not clearly made out. We have the fact that light falling on the platinum electrode of a voltameter generates a current, first observed, I think, by Sir W. R. Grove

at any rate it is mentioned in his "Correlation of Forces"extended by Becquerel and Robert Sabine to other substances, and now being extended to fluorescent and other bodies by Prof. Minehin. And finally-for I must be brief-we have the remarkable action of light on selenium. This fact was discovered accidentally by an assistant in the laboratory of Mr. Willough by Smith, who noticed that a piece of selenium conducted electricity very much better when light was falling upon it than when it was in the dark. The light of a candle is sufficient, and instantaneously brings down the resistance to something like one-fifth of its original value.

I could show you these effects, but there is not much to see ; it is an intensely interesting phenomenon, but its external manifestation is not striking - any more than Faraday's heavy glass experiment was.

This is the phenomenon which, as you know, has been utilised by Prof. Graham Bell in that most ingenious and striking invention, the photophone. By the kindness of Prof. Silvanus
Thompson I have a few slides to show the principle of the invention, and Mr. Shelford Bidwell has been good enough to lend me his home-made photophone, which answers exceedingly well for short distances.

I have now trespassed long enough upon your patience, but I must just allude to what may very likely be the next striking popular discovery, and that is the transmission of light by electricity; I mean the transmission of such things as views and pictures by means of the electric wire. It has not yet been done, but it seems already theoretically possible, and it may very soon be practically accomplished.

\section{ENDOWMENT OF RESEARCH IN BIRMINGHAM}

THE President of the Birmingham Philosophical Society, Dr. Heslop, recently gave an address to the members, taking for his sulject the "Scientific Situation in Birmingham." Having reviewed the various local agencies set up during the past year for the diffusion of knowledge, including the opening of Mason's Science College, he went on to say : I must now allude to the most important work undertaken by the Society, the establishment of the fund for the endowment of research. This action has received warm support in many quarters, and has in fact done more to place it in a favourable light before the country than any previous circumstances. Although the efforts made to raise this fund have been inconsiderable, yet nearly $100 \%$ in annual subscriptions, of varying dates, and gool. in donations have been obtained. The Council have invested $600 \%$. in order to ensure the permanence of the fund. It is probable that some slight additions may be made to this sum, having the same object in view; but it is, I believe, their intention to recommend the Society to spend the whole income, howsoever derived, in annual grants to persons living in this town or neighbourhood who devote themselves wholly or in part to science research. It is an error to suppose that this fund is to be allotted either to any particular individual or specially to members of this Society. The Council are free to do what they deem best with the money intrusted to them, within the limits of the scheme agreed upon. There is another temporary limit to their powers. One eminent investigator (Dr. Gore) is allotted a certain sum for a certain period. The approval of this step evinced by those who have contributed to the fund, and by others, has been a source of satisfaction to the Council.

I wish now to remind you that the scheme in connection with this subject declares that "the Council are of opinion that this Society would be omitting a principal means of the advancement of science-the end for which all such associations exist-if it neglected the question of the endowment of research. To maintain a successful investigator in his labours, even though no results of immediate or obvious utility can be shown to spring out of them, is of interest to the community at large." It may be that you will pronounce these words to be truisms scarcely requiring formal enunciation. The fact is that though the sense of them has been repeatedly given to the public in late years, practical action has not ensued. Everybody is telling his neighbour what a good thing it would be if men endowed with an aptitude for research into the facts of nature were also endowed with the means of living during their work. The speaker and the listener go by on the other side, and no good Samaritan tenders belp to the well-praised searcher after truth. Nay, Mr. Mark Pattison affirms in his late book on Milton that "the England of our day has decided against the endowment of science," and seems to think that the principle on which the decision is based may be wrong, but "is not unreasonable." But the endowment of ministers of science stands on quite another foundation from that of ministers of religion. "To assign a place with a salary," says Mr. Pattison, "is to offer a pecuniary inducement to simulate" the qualification, i.e. a state of grace. But in the case of science there is no question of place, and the endowment is offered, not to those who promise much, but to those who have already performed something; not to those who imagine themselves to be in the requisite spiritual state, but to those who, working for an atdience, select though few, have demonstrated that they are touched by the divine fire which burns not for other men.

In the opinion of others the only practicable mode of dealing with this question is by bestowing adequate funds on teachers, and by placing them in favourable conditions for research. 
The necessity for making provision for the devotion of fit men to scientific work has occurred to many, and doubtless private generosity has often enabled such men to prosecute labours by which the world has greatly gained. One of the most striking instances is that of Priestley. His own remarks contained in his diary are full of interest. $\mathrm{He}$ says that $\mathrm{Dr}$. Fothergill "having observed that many of my experiments had not been carried to their proper extent on account of the expense that would have attended them," proposed a subscription from himself and some of his friends, and named rool. per annum. $\mathrm{He}$ consented to receive $40 l$., which was regularly paid to him, three other gentlemen aiding. Afterwards for good reasons Fothergill proposed "an enlargement of the allowance for my experiments, and likewise for my maintenance, without being under the necessity of giving my time to pupils, which I must otherwise have done." This was accepted, as Priestley preferred it to any pension from the Court. He gives a minute list of the numerous donations, legacies (one of $2000 \mathrm{l}$.) and subscriptions given to him, while he dilates on Mr. Wedgwood's gifts of pottery, retorts, tubes, \&c., and presents in glass from another gentleman, among which figures "a capital burning-lens, sixteen inches in diameter." The Duke of Grafton remitted him annually $40 \mathrm{l}$. When be went to America forty of his friends, withour solicitation, raised the sum of 450 ?., "which was meant to have been continued annually while he lived," as stated by his son.

You will hear these details with the interest naturally belonging to the subject, and doubtless ask the question, Have succeeding generations improved on this? I believe that there is no example of an equal generosity on the part of their fellow-countrymen to a man of science, although there are some agreeable exceptions to the rule of neglect. A few years ago the Fishmongers Company presented the sum of $50 l$. to Prof. Parker, and an annual gift of $20 l$. for three years, to assist him in bearing the expense of his researches on vertebrate animals. For three years the British Pharmaceutical Society voted $8 \mathrm{o}$. in aid of pharmaceutical research. The principle of promoting research has also been recognised by the Government in their grant of roool., and in the fund of $4000 \%$. placed at the disposal of the Royal Society. Our Government hai, however, as yet made no payment for the labour of pure research in experimental physics or chemistry. "A grant from the above sum," says Dr. Gore, " 1 s often an unprofitable gift to accept, because it is in some cases only sufficient to pay expenses out of pocket for chemicals and apparatus, and allows nothing for skill or labour.'

The mention of our able associate's name compels me to draw attention to the invaluable services he has rendered for ten years past to the cause of the endowment of research. His numerous articles and papers form a repository of facts and arguments of which I have largely availed myself. Any one who studies them will need no other evidence of the importance of the question, both in view of the progress of truth and of the maintenance of our national welfare. In one of them he mentions the difficulty experienced in the proper employment of the Government money, and proceeds as follows:- "By far the greater part of the expense of an inve tigation in physics or chemistry is the exceedingly large amount of time it occupies. Many necessary preliminary experiments have to be made, which yield either negative, unsuccessful, or incomplete results, and make the undertaking expensive." Further, "By order of the Council, all instruments, apparatus, and drawings, made or obtained by aid of the Government grants, shall, after serving the purpose for which they were procured, and in the absence of any undertaking to the contrary, be delivered into the custody of the Royal Society."

Research, then, in any fair sense of the word may be said to be unprovided for by public funds. The British Association annually bestows grants of varying amounts for specific researches. The Royal Institution helps. Yet we feel surprised when told that the average annual expenses relating to experimental research, including salaries to assistants in the laboratory, from the year 1867 to $187 x$, did not amount to two hundred and fifty pounds.

When it is remembered that not a single college, nor even a professorship, for pure scientific research exists in this country, we must feel humiliated when we cast a glance at what is going on in other countries. In France and Germany varied resources have been placed at the disposal of men of science, which I cannot now minutely specify. Nor will I delay to speak in detail of the importance of pure research in science, of the mighty material results as regards our comfort and national wealth which have sprung from the labours of men of science, for it may be assumed that all this is known. It is certain too that valuable inventions in various arts and manufactures will follow upon fresh discoveries regarding the principles involved in them. When we know more of the materials and forces of nature, new applications of them will soon follow. The progress of invention depends upon that of discovery; the various inventions wanted by manufacturers and others cannot be perfected until "suitable knowledge is found." The money of the capitalist, the hand of the inventor, await the products of the brains of the searcher after truth.

It is only too well known that other countries have for some years past distanced Britain in the field of research; that while Germany is sending her trained sons to all parts of the world, we scarcely even supply our own colonies. A writer in the Monthly Fournal of Science said last year that " to a very great extent, both in the home kingdoms and the colonies, we find ourselves compelled to import that intellectual eminence which we refuse to cultivate in our midst. Foreigners occupy professorial chairs in our colleges; they fill the posts of botanists and geologists in our colonial governments; they hold high positions in the respective staffs of the British Museum, of the Geological Survey of India, and of our exploring expeditions."

Now as these results cannot be owing to any inbred deficiency in the countrymen of Newton, Faraday, and Darwin, it behoves us to ask if our educational system is at fault, and if fair provision is made for those able and willing to make original research. The latter question is already answered by the facts adduced. How far our great universities have provided for science-teaching can be learned by reading between the lines of certain resolutions passed a few years ago by an "Association for the organisation of academical study," the composition of which was an ample guarantee of competence. The resolutions were as follows :-

"That the chief end to be kept in view in any redistribution of the revenues of Oxford and Cambridge is the adequate maintenance of nature study and scientific research, as well for their own sakes as with the view of bringing the higher education within the reach of all who are desirous of profiting by it."

"That to have a class of men whose lives are devoted to research is a national object."

"That it is desirable in the interests of national progress and education that professorships and special institutions shall be founded in the universities for the promotion of scientific research."

"That the present mode of awarding Fellowships as prizes, has been unsuccessful as a means of promoting nature study and original research, and that it is therefore desirable that it should be discontinued.

The state of things here pointed at has improved and is improving, yet the verdict of a candid observer must still be summed up in the one word inadequacy.

Numerous suggestions have been made regarding the endowment of research, but most of them are unpractical. Those who imagine that the object will be gained by establishing adequate teacherships of science, seem to be too sangrine. The labour involved in the work of teaching, in the way of acquisition, preparation, and performance, is too great to permit the devotion of sufficient time and thought to the search after new truth. If it is desirable that new facts and principles be searched after, why should fit inquirers be put, either partly or wholly, to other work? I know that many of our teachers have hitherto been at a great disadvantage; that managers of institutions have had a sharper eye on their prospectus than on their internal arrangements; that they have thought of a college rather as a body of bricks than as productive of a body of learning; and that apparatus and assistants, though well enough in Berlin or Leipzig, are needless in prudent England. Yet the ideal Professor is rather the head of a department than a mere speaker by the yard of so many lectures; a man with numerous hands in the shape of denonstrators and assistants, themselves the possessors of welltrained brains; a director of work with all its apparatus freely supplied to him. Such a man adequately remunerated may be safely left to his own tendencies. Contact with nature breeds the desire to know her better. In favourable conditions the teacher becomes the investigator, and while seeking after new truth builds up his own fame.

After all, however, the question recurs, how can we best pro. mote research, as the undivided life's work of fit persons? I believe that the solution lies, so far as this time is concerned, in 
the establishment of special institutions having no other object than the search after new truth. Their administration would be difficult. The right men can be found for the work, but can the right electors be found? Ardent searchers after a more intimate knowledge of nature do still live, will ever live; but what of First Commissioners of Works like-but I need not name him? What of Lords of the Treasury who refused the request of a great physicist for $\mathbf{1 5 0 l}$. for the investigation of the tides? Yet these gentlemen assist in governing a maritime state of some importance. Such electors as these are not within my view, and, if they were, how of the detailed management? Men given up to research are not to be tied by the common rules of official life; to be compelled to report in annual blue books the exact measure of work they have done; to show how many drachnis of oil of vitriol they have used, and account for every ounce of platinum.

Special institutions will be founded, but they will owe their origin to private individuals like Sir Josiah Mason; who, having taken into their confidence the chiefs of the world of science in making the appointments, will speak to the masters of research in this wise :-

"I have built a house for you replete with every requirement for your work; I have provided you with such assistants as you have asked for; I have given you an income placing within your reach every reasonable comfort. Occupy your lives in the study of nature. If you succeed in your efforts to attain to new truth, the world will be the gainer. If you fail, your efforts will be enough reward for me."

Such language as this will be surely one day heard. In this fortunate town it is already heard. During the past year a member of this Society, Mr. Fulford, has taken a house, and, having admirably fitted it up, has handed it over to our two distinguished associates, Dr. Gore and Dr. Norris, in order that they may enjoy at least the requisite structural conveniences for the prosecution of research. This building is called the "Institute of Scientific Research."

I must, however, remind you that this noble enterprise must be supplemented by some such efforts in the way of endowment as those now made by this Society; and that those who work even in the highest sphere are bound by the same necessities as bind other men.

\section{SCIENTIFIC SERIALS}

Annalen der Physik und Chemie, No. 12 (December, first No.). -On the density and tension of saturated vapour, by $A$. Wiill ner and O. Grotrian.-On the application of the electrodynamic potential to determination of the ponderomotive and electro motive forces, by R. Clausius. - - On friction in free liquid surfaces, by A. Oberbeck. - Simple methods and instruments for resistance-measurements, especially in electrolytes, by F. Kohlrausch.-Influence of temperature on the phenomena of charge of a liquid cell acting as condenser, by H. Herwig.- On the modes of electric discharge in gases, by $\mathrm{O}$. Lehmann.--On the electric discharge in liquid insulators, by W. Holtz.- - On electric figures on the surface of liquids, by the same.--On the increase of danger from lightning and its probable causes, by the same. -On a microprismatic method for distinction of solid sub stances, by O. Maschke. - Note on Herr Weber's reply, by A. Winkelmann.

Reale Istituto Lombardo di Scienze e Lettere. Rendiconti. Vol. xii., fasc. xix. - The Leprosy of Upper Italy, especially of Comacchio (continued), by Prof. Sangalli.--Influence of traction and vibration of a metallic wire on its electric conductivity, by Dr. de Marchi.--On a case of twisted neck; a contribution to the doctrine of transport of spinal influence and to establishment of a hypothesis for its explanation, by Prof. de Giovanni.

Zeitschrift für wissenschaftliche Zoologie, November, 1880, contains : Dr. H. von Ihering, on the affinities and kinship of the Cephalopods.-Dr. J. Bellonci, on the origin of the optic nerve and on the minute structure of the "tectum opticum" in the Teleostei (PIates $I$ and 2).-Dr. D. Sochaczewer, on the organ of smell in the terrestrial pulmonates (Plate 3).-Dr. Fritz Muiller, on the case-making Trichoptera larvæ of the Province of Santa Catharina (Plates 4 and 5), translated by his brother, Dr. Hermann Müller, from the memoirs in Portuguese in the Archivos de Museu National, Rio de Janeiro.-Dr. William Marshall, researches in the sponge groups, Dysideidæ and Phoriospongix (Plates 6 to 8).-Prof. Dr. Krause, on two very early human embryos (Plate 9).-Dr, H. Simroth, on the nervous system in the foot of Paludina vivipara, with a woodcut of the nerves as dissected out.

Retue internationale des Sciences biologiques, iDecember 1880 contains:-A. de la Calle, on the formation of language (continued). -M. Decatte, microcephalism, from the point of view of atavism. -M. Zaborowski, historical sketch of the relative knowledge possessed by the ancients and in medixval times of the large monkeys.-Notices of learned societies.-French Association for the Advancement of Science (the Rheims Meeting). - The Academy of Sciences, Paris.

Schriften der physikalisch-ökonomischen Gesellschaft zu Königs. berg (1877, ii. ; 1878, i. and ii.).-These parts contain the following papers:-On Baron von Richthofen's loess theory and the alleged steppe character of Europe at the close of the Glacial period, by Dr. A. Jentzsch.-Observations of the station for measuring the tem erature of the soil in various depths, at the Königsberg Botanical Gardens, by Prof. E. Dorn.-On the prehistoric-archæological work done by the Society, by Otto Tischler.-On the commercial routes of the ancients to the amber country, by Dr. Krosta.-On the physics of the soil, by Dr. von Liebenberg.-On the discoveries in prehistoric tombs at Fürstenwalde, by Otto Tischler.-On hair-covered buman beings and the abnormal growth of bair, by Prof. Hildebrandt.- On the marine fauna near the Prussian coast, by Prof. Zaddach. On the alleged steppe character of Central Europe, by Dr. Ientzsch. - On the state of civilisation in Denmark during the first centuries after Christ, by O. Tischler.-On Darwin's theory, by Herr Czwalina.-On East Prussian burial-grounds, by $O$. Tischler.-On the fauna of Madagascar, by Prof. Zaddach.-On the intra-Mercurial planet, by Dr. Franz,-On the geological maps at the Paris Exhibition. by Dr. Jentzsch. - On some special geological maps of Germany, by the same.-On the principles of the kinetic theory of gases, by Dr. Saalschuitz.

\section{SOCIETIES AND ACADEMIES LONDON}

Chemical Society, January 20.-Prof, H. E. Roscoe, president, in the chair.- The president announced that the Faraday lecture would be delivered by Prof. Helmholtz in the Royal Institution, On the Modern Development of Faraday's Conception of Electricity. The following papers were read :-On pentathionic acid, by Mr. V. Lewes. The author has succeeded in obtaining beautifully crystallised barium and potassium penta. thionates by partially neutralising Wackenroder's solution and evaporation in vacuo. -A preliminary note on some hydrocarbons from rosin spirit, by Dr. Armstrong. Cymene, toluene, and metaxylene were found to be present. The hydrocarbons insoluble in sulphuric acid are probably hexhydrides of hydro. carbons of the benzene series. The author does not consider that rosin is directly derived from terpene.-On the determination of the relative weight of single molecules, by Dr. Vogel of San Francisco.-On the synthetical production of ammonia by the combination of hydrogen and nitrogen in presence of heated spongy platinum, by G. S. Johnson. A bout 0*0144 grm. of ammonia were obtained in two and a half hours.-Gn the oxidation of organic matter in water, by A. Downes.-Analyses of Queensland soils, by Prof. A. Liversidge. These analyses are interesting, as the soils include samples from districts which were exempt from the disease prevalent in the sugar plantations around.-On the volumes of some compounds of the benzene naphthalene, anthracene, and phenanthrene series, by Dr. Ramsay.-On the atomic volume of nitrogen, by Dr. Ramsay.On a new theory of the conversion of bar iron into steel by the cementation process, by Dr. Marsden. The author thinks that carbon diffuses in an impalpable powder through the heated iron. $\rightarrow$ On the action of sulphydrate of potassium on chloral hydrate, by W. W. J. Nicol. Thioglyoxylic and thioformic acids are formed.

Zoological Society, January 18.-Prof. W. H. Flower, LL.D., F.R.S., president, in the chair.-The Secretary read a report on the additions that bad been made to the Society's Menagerie during the month of December, 1880, amongst which special attention was called to a young female Red Wolf (Canis jubatus) from the Argentine Republic, presented by Mr. W. Petty of Monte Video, being the second example of this scarce animal received, and to a Pig from Brooker Island, Louisiade Archipelago, presented by Lieut. de Hoghton, of H.M.S. 